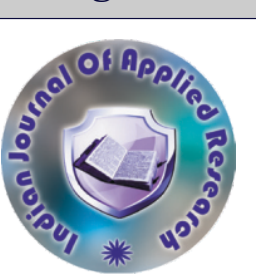

\title{
C Neurosurgery \\ "DETERMINANTS OF ACADEMIC SATISFACTION OF NEUROSURGERY RESIDENTS -BASED ON A CROSS SECTIONAL QUESTIONNAIRE SURVEY IN KERALA."
}

Dr. Vinu. V. Gopal*

\section{Prof P. K. Balakrishnan \\ ABSTRACT}

Associate professor, Department of Neurosurgery, Govt medical college, Kottayam. *Corresponding Author

\author{
Professor, Department of Neurosurgery, Govt medical college, Kottayam.
}

INTRODUCTION: Surgical training is different from medical training where resident learns from doing surgeries and observing surgical skills from the senior faculty in addition to reading books. There is insufficient literature regarding the lacunae in current surgical training in our medical colleges. Aim of the survey is to identify the determinants of academic satisfaction of neurosurgery residents undergoing the present surgical training program in kerala.This survey determines the factors affecting academic satisfaction from a student perspective which will definitely be an eye opener regarding the benefits as well as drawbacks of the present curriculum in Kerala. MATERIALS AND METHODS: A descriptive cross sectional survey of neurosurgery residents was done using a prevalidated questionnaire and send by email . It covered demographics, the overall satisfaction and variables related to aspects of residency training like 1)surgery related 2)clinical care related 3) education related variables which are collected on a 5 point leikert score scale and scored. Responses obtained were enterd in SPSS data sheet and analysed . RESULTS: The response rate was $60 \%$. The average age of surgery residents in our survey was $30.4 \pm 2.59$ years, majority being males $(83 \%)$. Majority $(41.7 \%)$ of residents who participated and responded to the survey were satisfied with the current surgical training. The residents were more satisfied if 1)faculty allowed residents to perform the important steps in the operations but without being overly supervised $(\mathrm{p}=0.049) 2$ ) if they scrubbed more than 25 cases last month $(\mathrm{p}=.011)$; and 3 ) if they involve with the faculty in management decisions.( $\mathrm{p}=.032)$. CONCLUSION: The survey highlighted that faculty should support and give residents freedom to share a keyrole in patient management decisions .Improving resident satisfaction may help encourage more medical students to enter neurosurgical profession. Present survey will definetly guide curriculum management committees in health universities

\section{KEYWORDS : SATISFACTION,ACADEMIC,SURGERY,RESIDENTS,TRAINING}

\section{INTRODUCTION}

Surgical training is different from medical training where resident learns from doing surgeries and observing surgical skills from the senior faculty in addition to reading books ${ }^{6}$. There is insufficient literature regarding the lacunae in current surgical training in our medical colleges.

Aim of the survey is to identify the determinants of academic satisfaction of neurosurgery residents undergoing the present surgical training program in kerala. Healthy faculty- resident interaction, both in the operating room and in the ward are important for better surgical training ${ }^{7,8,10}$. An important question for surgical faculty is how to optimize faculty interactions with residents for improving quality of training ${ }^{11,12}$.This survey determines the factors affecting academic satisfaction from a student perspective which will definitely be an eye opener regarding the benefits as well as drawbacks of the present curriculum in Kerala.Satisfaction is an important outcome measure because it highlights the perspective of learners and serves to change the attitude of surgery faculties for improving surgery resident satisfaction and, possibly medical education

\section{MATERIALSAND METHODS}

A descriptive cross sectional survey was done on $60 \mathrm{MCh}$ Neurosurgery trainees (present academic year) )and senior residents(post $\mathrm{MCh}$ ), using a non probability sampling technique, presently working in teaching hospitals of kerala(both govt and private) was done. Institutitional IRB approval was obtained from the instituition were the author is working.

Survey questions were prepared and entered in Google forms. Survey was initially validated among four neurosurgeons working in four different districts of kerala. Corrections were made as per their suggestions, which we felt improved the readability of the questionnaire. Final form was sent by e- mail to neurosurgery trainees of the present academic year .Non responders were again contacted at 4 and 6 weeks and study was closed on 12th week. The questionnaire used is given in Figure 1

Data was entered in SPSS version 16 (SPSS Inc., Chicago, IL, USA). Variables used in in study include

1) Resident demographics like age, gender, marital status, number of children, residence,present academic status and educational debt

2) Variables related to aspects of surgical residency training like 1)surgery related 2)clinical care related 3 ) education related variables was collected on a 5 point leikert score scale.
3) The outcome variable(dependent variable)-overall satisfaction was resident satisfaction. Response categories used was : "very satisfied" "satisfied" ,"neither satisfied nor dissatisfied"or "dissatisfied","very dissatisfied" on a 5 point likert scale and scored.For the sake of convenience for analysis ,first three on leikert scale are classified as "satisfied "and the next two on leikert scale were classified as "dissatisfied "on final analysis

Descriptive analysis along with univariate and multivariate analysis was done and determinants were found out by logistic regression.Odds ratio and $\mathrm{P}$ value was determined to identify determinants of resident satisfaction

\section{Figure 1 QUESTIONNAIRE used for the survey}

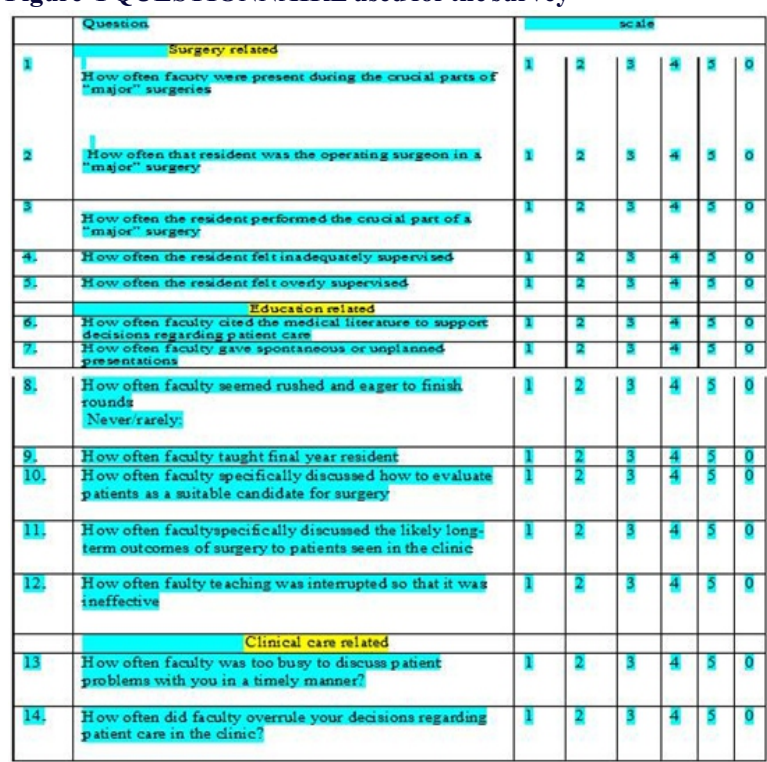

\section{RESULT}

Of the 60 surveys which were received at the recipient e mail addresses, 40 were returned and thus response rate was $67 \%$. But four surveys were incomplete and hence were discarded from the analysis. So the study is based on the analysis of practices of 36 neurosurgery residents (all years) working in different parts of the state 


\section{Descriptive Analysis}

\section{RESIDENT DEMOGRAPHICS}

The average age of surgery residents in our survey was $\mathbf{3 0 . 4} \pm \mathbf{2 . 5 9}$ years. Most were male $(\mathrm{n}=30,83 \%), 80.6 \%(\mathrm{n}=29)$ were married and $38 \%$ had children (Table 1 ).

Table1:Demographics Of Respondents Who Participated In Survey

\begin{tabular}{|l|l|l|l|}
\hline Gender & & Frequency & Percentage \\
\hline & Male & 30 & 83.3 \\
\hline & Female & 6 & 16.7 \\
\hline Present academic & & & \\
\hline & Regular & 22 & 61.1 \\
\hline & Repeator & 2 & 5.6 \\
\hline & Senior Resident & 12 & 33.3 \\
\hline Residence & & & \\
\hline & Day Scholar & 11 & 30.6 \\
\hline & Hostel & 21 & 58.3 \\
\hline & Other & 4 & 11.1 \\
\hline MaritalStatus & Married & 29 & 80.6 \\
\hline & Unmarried & 7 & 19.4 \\
\hline Ifyesno.OfChild & & & \\
\hline & 0 & 18 & 62.1 \\
\hline & 1 & 9 & 31.0 \\
\hline & 2 & 2 & 6.9 \\
\hline Education debt & & & \\
\hline & YES & 12 & 33.3 \\
\hline & NO & 22 & 61.1 \\
\hline
\end{tabular}

Majority were hostel inmates(58.3\%(n=21)(Table 1)33.3\% had debts in the form of educational loans .Majority $(41.7 \%, n=30)$ of surgery residents who participated and responded to the survey were satisfied with the current surgical training.

\section{SURGERY-RELATED VARIABLES AFFECTING RESIDENT SATISFACTION}

The survey questionnaire covered a number of issues regarding the operative experiences of the residents. Response to questionnaire and its frequencies are shown in Table 2.

Table 2: Response frequency of surgery related variables influencing surgery resident satisfaction.

\begin{tabular}{|l|l|l|l|}
\hline QUESTION & RESPONSE & N & \% \\
\hline $\begin{array}{l}\text { How Often Operating } \\
\text { Surgeon In Major } \\
\text { Cases? }\end{array}$ & & & \\
\hline & Never & 4 & 11.1 \\
\hline & Rarely & 17 & 47.2 \\
\hline & Sometimes & 9 & 25.0 \\
\hline & Often/always & 6 & 16.7 \\
\hline $\begin{array}{l}\text { Performed Crucial Parts } \\
\text { of Major Surgery }\end{array}$ & & & \\
\hline & Never & 4 & 11.1 \\
\hline & Rarely & 16 & 44.4 \\
\hline & Sometimes & 11 & 30.6 \\
\hline & Often/always & 5 & 13.9 \\
\hline $\begin{array}{l}\text { How Often Inadequately } \\
\text { Supervised? }\end{array}$ & & & \\
\hline & Never & & 38.9 \\
\hline & Rarely & & 22.2 \\
\hline & Sometimes & & 30.6 \\
\hline & Often/always & & 8.4 \\
\hline Felt Overly Supervised & & & \\
\hline & Never & 9 & 25.0 \\
\hline & Rarely & 12 & 33.3 \\
\hline & Sometimes & 11 & 30.6 \\
\hline & Often/always & 4 & 11.1 \\
\hline
\end{tabular}

The mean number of surgeries per month in which the resident actually scrubbed was $24.67 \pm 12.4$. The respondent was the operating surgeon for a mean of 12 cases/month. Forty five percent of the residents reported that they almost always performed the crucial parts of major surgeries(ie, $>6 \mathrm{hrs}$ ), whereas $56 \%$ reported it as rarely or never Seventy five percent of respondents reported that supervising surgeons were present almost always during the crucial parts of major surgeries.Only $16.7 \%$ of residents performed the role of operating surgeon. Sixty one percent of the residents rarely or never felt inadequately supervised during major surgeries; however $12 \%$ often or always felt overly supervised.

This is shown in table 2 .

\section{EDUCATION-RELATED VARIABLES AFFECTING RESIDENT SATISFACTION}

$50 \%$ of respondents reported that faculty often cited the medical literature to support their decisions in patient care. $20 \%$ of respondents reported that surgeons often rushed and eager to finish rounds, and over $44 \%$ sometimes felt that faculty surgeons were interrupted due to busy schedule such that their teaching was ineffective...Bar chart showing response given were given in figure 2

\section{Education related}

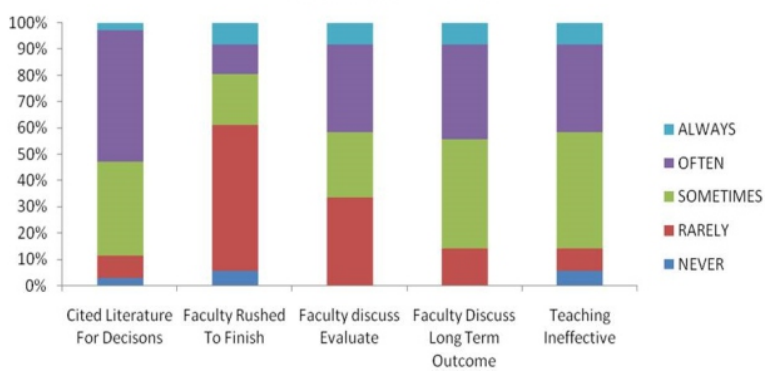

Figure 2: Response Percentage Of education Related Variables Influencing Resident Satisfaction

\section{CLINICAL CARE-RELATED VARIABLES AFFECTING} RESIDENT SATISFACTION

Twenty seven percent of respondents reported that surgical teachers were rarely too busy to discuss patient problems. Moreover, the majority of important postoperative patient management decisions were made with the resident and faculty (67\%) compared to the faculty alone in $33 \%$ of cases .(Table 3 )

TABLE3: Response frequency of clinical related variables influencing surgery resident satisfaction

\begin{tabular}{|l|l|l|l|}
\hline QUESTION & RESPONSE & N & \multicolumn{2}{l|}{} \\
\hline How often Faculty is Too Busy & & & \\
\hline & Never & 3 & 8.3 \\
\hline & Rarely & 7 & 19.4 \\
\hline & Sometimes & 14 & 38.9 \\
\hline & Often & 11 & 30.6 \\
\hline & Always & 1 & 2.8 \\
\hline $\begin{array}{l}\text { How often Faculty Overrule resident } \\
\text { Decisions }\end{array}$ & & & \\
\hline & & & \\
\hline & Rarely & 9 & 25.0 \\
\hline & Sometimes & 15 & 41.7 \\
\hline & Often & 9 & 25.0 \\
\hline How often faculty Actually See Post Op & Always & 3 & 8.3 \\
\hline & $<1 / 2$ & & \\
\hline & $1 / 2$ & 5 & 13.9 \\
\hline & $>1 / 2$ & 14 & 38.9 \\
\hline Who Made Management Decsion? & & 17 & 47.2 \\
\hline & You Qnd & 24 & 66.7 \\
\hline & Faculty & & \\
\hline & Faculty Alone & 12 & 33.3 \\
\hline
\end{tabular}

With regard to continuity of care of patients on whom they performed major surgery, $39 \%$ of respondents saw about half of them postoperatively and $14 \%$ reported seeing less than half of the patients

\section{DETERMINANTS OF RESIDENT SATISFACTION}

In this study, we find that male residents are more satisfied compared to female residents [figure 3] 


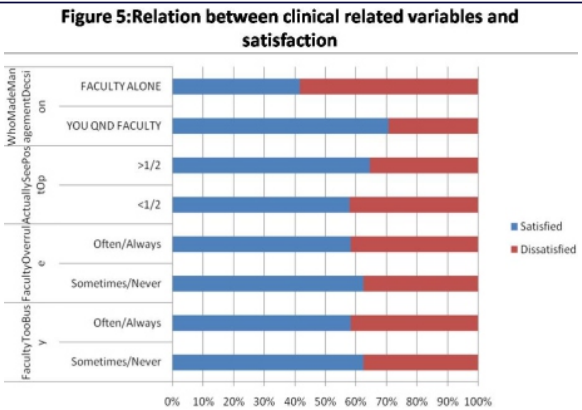

Out of the 36 respondents participated in survey, 29 were married. $59 \%$ students who were married were satisfied with their professional activities $71 \%$ unmarried were satisfied. Our study showed that $64 \%$ of hostel residents were satisfied compared to $54 \%$ among day scholars. From our study we found that, senior residents have higher satisfaction levels compared to residents less than 30 years $(71 \%$ vs $52 \%$ ). We now present results from the logistic analysis of factors that determine surgery resident satisfaction. We group the discussion of determinants into 3 areas (surgery, education, and clinical carerelated). Of 7 possible surgery-related variables, only 2 variables were statistically significant $(\mathrm{P}<0.05)$. The variable significantly associated with increased satisfaction was being the resident being the operating surgeon in major surgeries (odds ratio $\mathrm{OR}=2.91 ; \mathrm{P}=0.049$ ) [Table4].

Table 4:Univariate Analysis Showing Significant Factors Influencing Surgery Resident Satisfaction

\begin{tabular}{|c|c|c|c|c|c|c|c|c|c|c|}
\hline & \multicolumn{2}{|c|}{$\begin{array}{l}\text { Satisfie } \\
\text { d }\end{array}$} & \multicolumn{2}{|c|}{\begin{tabular}{|l|} 
Dis \\
satisfie \\
d
\end{tabular}} & \multicolumn{2}{|c|}{ Total } & \multirow[t]{2}{*}{$\chi^{2}$} & \multirow[t]{2}{*}{$\overline{\mathrm{df}}$} & \multirow[t]{2}{*}{ p } \\
\hline & & $\mathrm{N}$ & $\%$ & $\mathrm{~N}$ & $\%$ & $\mathrm{~N}$ & $\%$ & & & \\
\hline \multirow{2}{*}{\begin{tabular}{|l|} 
No of \\
Surgery \\
scrubbed
\end{tabular}} & $<25$ cases & 9 & 47.4 & 10 & 52.6 & 19 & 100 & & & \\
\hline & $>25$ cases & 13 & 76.5 & 4 & 23.5 & 17 & 100 & \begin{tabular}{|l|}
6.395 \\
\end{tabular} & 1 & 0.011 \\
\hline \multirow{2}{*}{$\begin{array}{l}\text { How often } \\
\text { Operating } \\
\text { surgeon }\end{array}$} & $<10$ cases & 9 & 47.4 & 10 & 52.6 & 38 & 100 & & & \\
\hline & $>10$ cases & 13 & 76.5 & 4 & 23.5 & 34 & 100 & 6.395 & 1 & 0.011 \\
\hline \multirow[t]{2}{*}{ Gender } & Male & 20 & 66.7 & 10 & 33.3 & 60 & 100 & & & \\
\hline & Female & 2 & 33.3 & 4 & 66.7 & 12 & 100 & 4.675 & 1 & 0.031 \\
\hline \multirow{2}{*}{$\begin{array}{l}\text { Who Made } \\
\text { Manageme } \\
\text { nt Decision }\end{array}$} & $\begin{array}{l}\text { You and } \\
\text { Faculty }\end{array}$ & 17 & 70.8 & 7 & 29.2 & 48 & 100 & & & \\
\hline & $\begin{array}{l}\text { Faculty } \\
\text { Alone }\end{array}$ & 5 & 41.7 & 7 & 58.3 & 24 & 100 & 5.727 & 1 & 0.017 \\
\hline
\end{tabular}

Another factor associated with increased satisfaction on univariate analysis was the number of surgeries in which the resident scrubbed last month.The residents were more satisfied if they scrubbed more than 25 cases last month $(\mathrm{p}=.011)$. No other surgery related factors were found to be related to resident satisfaction.None of the educationrelated variables were statistically associated with resident satisfaction. The clinical- related variable associated with increased satisfaction was regarding who made management decisions

Residents are seen to be more satisfied if they involve with the faculty in management decisions.(odds ratio $=3.153, \mathrm{P}=.032$ ) [Table 4] .Thus surgery residents were seen to be satisfied if they are involved in decision making. The reason may be that they feel psychologically at at par with consultants in decision making Relatioships of demographic,surgery related,education related and clinical care related variables to overall satisfaction is depicted in figure $3,4,5$.

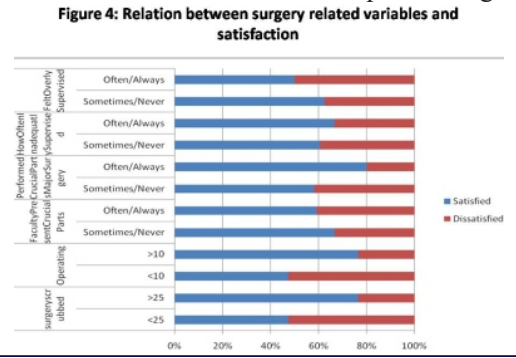

Univariate analysis showing the significant determinants of resident satisfaction is shown in Table 4.Final step of binary logistic regression( backward LR model) of factors for predicting surgery resident satisfaction is shown in Table 5.

Table 5: Final Step Of Binary Logistic Regression( Backward Lr Model) Of Factors For Predicting Surgery Resident Satisfaction

\begin{tabular}{|l|l|l|l|l|}
\hline $\begin{array}{l}\text { Significant Determinants Of } \\
\text { Resident Satisfaction }\end{array}$ & $p$ & OR & \multicolumn{2}{|l|}{ 95\% C.I.for OR } \\
\cline { 4 - 6 } & & & Lower & Upper \\
\hline $\begin{array}{l}\text { Performed role of Operating } \\
\text { Surgeon in Prior Month( }>10 \text { cases })\end{array}$ & .049 & 2.910 & 1.006 & 8.418 \\
\hline $\begin{array}{l}\text { Management Decsion Made by } \\
\text { resident himself }\end{array}$ & .032 & 3.153 & 1.107 & 8.987 \\
\hline Constant & .002 & .009 & & \\
\hline
\end{tabular}

\section{OVERALL SATISFACTION}

$41.7 \%$ of surgery residents were satisfied to supervised surgical training. $19.4 \%$ were very satisfied,compared to $16.7 \%$ who were dissatisfied

\section{Figure 6:}

\section{Figure 6 overall satisfaction}

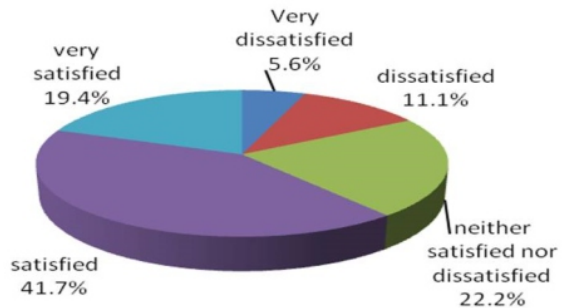

\section{LIMITATIONS}

Small sample size due to $60 \%$ response rate and response bias are the major limiting factor.

\section{DISCUSSIONAND REVIEW OF LITERATURE:}

The aim of our study was to find out the determinants of surgery resident's satisfaction to the present surgical training program and the influence of demographic,surgery related, education related and clinical care related variables on resident satisfaction.

The overall satisfaction rate in our study was $42 \%$. This is lower in reported studies in literature which reported around $90 \%$ satisfaction rate $^{1}$.This itself show that we need to improve in the field of medical education.

\section{Gender}

In this study, we find that male residents are more satisfied compared to female residents [figure].These findings are consistent with other studies, Tessema et $\mathrm{al}^{2}$ and Ziae et al. ${ }^{3}$.This may be because females had more family responsibilities than their male counterparts

\section{Marital status}

In the survey questionnaire, a question was included about the marita status in order to find out whether the marriage affected their academic satisfaction as the added responsibilities are more after marriage. Out of the 36 respondents participated in survey,29 were married. 59\% 
students who were married were satisfied with their professional activities $71 \%$ unmarried were satisfied. Our findings were similar to the studies done by researchers from King Faisal University, Saudi Arabia ${ }^{4}$.

\section{Hostel life}

We also investigated whether surgery resident who stay in hostel has more academic satisfaction compared to a day scholar.Our study showed that $64 \%$ of hostel residents were satisfied compared to $54 \%$ among day scholars. The increased satisfaction among hostel inmates may be due to the team work and social communication among inmates which facilitated learning.Our finding is discordant with many other studies which stated that the lack of satisfaction in the hostels may be due to ill-equipped learning environment in hostels ${ }^{5}$.

\section{Financial debts}

Surgery residents suffer many financial hardships due to educational loans .In our survery, students with educational debts are seen to have reduced academic satisfaction.Demands such a money for text books ,clothing, medical equipments during resident period affect their studies and satisfaction to some extend

\section{Faculty-resident interaction}

Healthy faculty-resident interaction, both in the operating room and in ward is important for better surgical training experiences ${ }^{6,7,8}$. An important question for surgical faculties is how to optimize such faculty interactions for quality training. Satisfaction is an important outcome measure because it highlights the perspective of learners and serves to change the attitude of surgery faculties for improving surgery resident satisfaction and possibly medical education. ${ }^{8,9}$

From our study we found that, senior residents have higher satisfaction levels compared to residents less than 30 years( $71 \%$ vs $52 \%)$. The reason may be that the faculty and residents gradually develop their relationships as time goes by. Thus, developing trust between mentors and mentees is very important. The success of mentoring highly depends on the mentor-mentee relationship

\section{Working hours}

Balancing clinical service demands with resident education will always be a challenge in any residency program ${ }^{1}$.In our survey $25 \%$ of respondents need to do administrative work of $3 \mathrm{hrs}$ which is not part of the curriculum and affected their academic satisfaction. The more the resident spend in the ward for academic purpose,the more they are satisfied.In our survey residents who spend more than $6 \mathrm{hrs}$ are more satisfied (63\%)than residents who spend less than 6 hours $(60 \%)$.

\section{Mode of surgical training and resident satisfaction}

Being inadequately supervised as well as being overly supervised negatively impacted satisfaction ${ }^{8,9}$.Athough it is important for faculty to give major cases individually to residents for academic exposure, the faculty must concomitantly provide the highest quality of care to their patients ${ }^{8,9}$. Achieving both tasks simultaneously may require some new model such as having the resident increasingly practice complex surgical techniques with simulators so that the residents become more proficient at surgery. Apprenticeship type model also would help facilitate resident development. We are in an era of increasing time demands in which more patients are being seen resulting in increased case loads. Time constraints are not easy to resolve and affects the quality of teaching and educational satisfaction. ${ }^{10}$

Faculty commitment for training residents and faculty motivation to educate residents play an important role in dynamics of any training programs. Thus faculty development and empowerment will positively affect the surgical training process. The resident's attitude and behaviour will have a major impact on operative satisfaction as literature says that residents must "earn" operative experience from faculties as a reward for good patient care in ward ${ }^{11}$.

In addition to surgery and education-related items, there were also clinical care-related variables associated with resident satisfaction ${ }^{12,13}$ Attending surgeons, who were often or always too busy to discuss patient problems in a timely manner is associated with lower satisfaction rates. ${ }^{7,12}$. Studies show that residents need to be involved in patient care decision-making, but also need the input of their teachers ${ }^{7,12}$. From our study it was seen that resident satisfaction was higher when the majority of important postoperative patient management decisions were made by the resident in consultation with faculty .Many of the above factors can be effectively changed to improve resident satisfaction.

Bedside teaching is seen as one of the most important modalities in teaching a variety of skills important for the medical profession, but its use is declining nowadays.. Bedside teaching has shown to improve certain clinical diagnostic skills in residents ${ }^{13}$. Participating in bed side teaching help in improving knowledge, attitude ,skills and patient care and proper patient communication.

\section{CONCLUSION:}

Our study will be an eye opener to faculty as overall satisfaction of surgery resident to present training program is only $41.7 \%$. The survey also highlighted the importance of the fact that faculty should continue to allow residents to perform the important steps in the operations but without being overly supervised. In addition, faculty should try to give evidence-based teaching presentations that are not rushed or interrupted by other duties so that teaching are effective. From our study it was clear that continuity of care and shared patient management decision-making helps in improving resident satisfaction.Improving resident satisfaction may help encourage more medical students to enter neurosurgical profession.Present survey will definetly guide curriculum management committees in health universities

\section{Acknowledgement:}

I specially thank my colleagues, Neurosurgery Department, MCI NODAL CENTER KOTTAYAM Medical college,Kottayam for providing support and help in preparing manuscript.

\section{REFERENCES}

1. Crewson PE, Sunshine JH. Professional satisfaction of US radiologists during a period of uncertainty: Radiology 1999; 213:589-597

2) Tessema MT, Ready K, Yu WC. Factors affecting college students' satisfaction with major curriculum: Evidence from Nine Years of Data. International Journal of Humanities \& social science .2012:2:34-44

3) Ziaee V, Ahmadinejad Z, Morravedji AR . An Evaluation on Medical Students Satisfaction with Clinical Education and its Effective Factors: Med Educ: 2004: 9: 8

4) Abou-Elhamd KEA, Al-Wadaani HA, Al-Mulhim ARS . Female medical undergraduate; does marriage affect the academic performance in a Saudi University Professional Med J.2014: 21(3):566-569

5) Morrish I. London: Allen \& Unwin. The sociology of education: An introduction:1968 pp. $65-89$.

6) Ko $\mathrm{CY}$ etal. Predictors for medical students entering a general surgery residency: National survey results. Surgery. 2004;136:567-72

7) Steinert $Y, M a n n ~ K$, Centeno A; Asystematic review of faculty development initiative to improve teaching experience in medical education;BEME guide No.8 Med Teach 2006;28:497-526

8) Reines HD etal A,defining service and education,First step to developing correct balance,Surgery 2007; 142:303-10

9) Nadol JB Jr. Training the physician-scholar in otolaryngology- head and neck surgery Otolaryngol Head Neck Surg. 1999;121:214-219

10) Organ $\mathrm{CH}$. The generation gap in modern surgery. Arch Surg. 2002; 137:250-252

11) Gabram SGA, Hoenig J, Schroeder JW. What are the primary concerns of recently graduated surgeons and how do they differ from those of the residency training years? Arch Surg. 2001;136:1109-1114.

12) Saarikoski M. Mentor relationship as a tool of professional development of student nurses in clinical practice. Int J Psychiatr Nurs Res. 2003;9: 1014-1024.

13) Dal U, Arifoglu B, Razi G What factors influence students in their choice of nursing in North Cyprus. Procedia Social and Behavioural Sciences.2009: 1924-1930 